\title{
Desenvolvimento de feijão-macuco em área de várzea.
}

\author{
Zilvanda L. de Oliveira Melo; Carlos Roberto Bueno \\ INPA, Caixa Postal 478, 69.011-970 Manaus-AM.
}

\section{RESUMO}

Entre as espécies tropicais que produzem tubérculos encontrase Pachyrrhizus tuberosus, conhecida popularmente como feijãomacuco ou jacatupé. Objetivou-se avaliar o crescimento da espécie correlacionando o desenvolvimento de órgãos da planta na fase vegetativa, de floração, de frutificação e da formação das raízes tuberosas, bem como avaliar a importância do tutoramento e da eliminação da inflorescência no desenvolvimento da planta e na produção das raízes tuberosas. O estudo foi realizado em área de várzea do Rio Solimões, no período de agosto de 1993 a maio de 1994, tendo-se verificado um total de $1.925 \mathrm{~mm}$ de chuva, temperatura média de $26^{\circ} \mathrm{C}$ e umidade relativa $86,5 \%$. Foi estudado o comportamento de três genótipos (definidos como 1, 2 e 3), submetidos a quatro formas de manejo: com e sem tutoramento das plantas e com e sem poda das inflorescências. O delineamento experimental utilizado foi o de blocos ao acaso em esquema fatorial 3 × 2 × 2 (respectivamente introduções, tutoramento e retirada das inflorescências). Foram utilizadas três repetições e as parcelas mediram 15,5 x 25,0 metros. $\mathrm{O}$ tratamento tutorado promoveu acúmulo da matéria seca dos frutos e do caule, resultando em maior peso da matéria seca da parte aérea. De maneira geral, no tratamento tutorado houve incremento ordenado das partes aérea e subterrânea. As taxas de crescimento dos genótipos estudados apresentaram um mesmo padrão de desenvolvimento das plantas. Houve tendência das plantas tutoradas de apresentarem maior crescimento relativo. A poda das inflorescências promoveu aumento considerável do peso das raízes tuberosas, chegando a aumentar em até 4,6 vezes, em comparação com o tratamento com inflorescências. Além de aumentar o peso da matéria seca das folhas, a poda das inflorescências favoreceu também um aumento nos teores de clorofilas a, b e total, aos 160 dias após a semeadura. Pelos resultados obtidos nesse trabalho, concluímos que o tutoramento das plantas, associado à remoção das inflorescências, favoreceu o desenvolvimento do feijão macuco.

\begin{abstract}
Development of yam bean or "Feijão-Macuco" plant in a floodplain area.

Pachyrrhizus tuberosus, popularly known as yam bean, ("feijão-macuco" or "jacatupé" in portuguese) is one of the tropical food plant species bearing edible tuberous roots. The purpose of this study was to evaluate the plant's growth, correlating the development of the plant parts in the vegetative, flowering, fruiting and tuberous root formation stages, as well as assessing the importance of staking the plants and pruning the inflorescence in the development of the plant and in the yield of tuberous roots. The study was carried out in a Rio Solimões' floodplain area from August 1993 to May 1994, with $1,925 \mathrm{~mm}$ of rainfall, $26^{\circ} \mathrm{C}$ average temperature and $86.5 \%$ relative humidity. The behavior of three genotypes, identified as 1 , 2 and 3, which were submitted to four kinds of plant management: with and without staking the plants and with and without pruning the inflorescences. The experimental design was completely randomized blocks in a factorial scheme of $3 \times 2 \times 2$ (genotypes, staking, and inflorescences pruning, respectively) with three replications. Plots measuring 15.5 × $25.0 \mathrm{~m}$ were used. The staking treatment increased the plant and stems dry matter weight. Usually there was a steady increase of the above and below ground parts with staking. Growth rates were similar to all genotypes. Staked plants showed a tendency to higher relative growth. The pruning of the inflorescences promoted up to 4.6 fold increase in the tuberous roots weight. In addition to raising the leaves dry matter weight, inflorescence pruning also furthered an increase in the $\mathrm{a}, \mathrm{b}$ and total chlorophyl grades 160 days after sowing. According to results obtained, it was concluded that staking plants associated with the pruning of the inflorescences improved the development of the "feijão-macuco".
\end{abstract}

Key Words: Pachyrrhizus tuberosus, staking, inflorescence

pruning, tuberous root formation, chlorophyl.
Palavras-chaves: Pachyrrhizus tuberosus, tutoramento, poda de inflorescência, tuberização, clorofila.

\section{(Aceito para publicação em 02 de fevereiro de 2.000).}

$P_{\mathrm{p} p}$ achyrrhizus tuberosus conhecida popularmente como feijão-macuco é uma planta herbácea, trepadeira podendo atingir de 30 centímetros a 3,5 metros de altura, formando uma ou mais raízes tuberosas, de casca marrom claro e interior branco. $\mathrm{O}$ fruto é um legume, medindo de 6,5 a $20 \mathrm{~cm}$ de comprimento. As raízes representam um alimento potencialmente importante para os trópicos, notadamente pelo conteúdo de proteínas, que pode alcançar até $9 \%$ do total da matéria seca (Noda et al. 1984; Sales, 1993).

Na literatura, alguns trabalhos mostram que a prática de determinados tratos culturais podem otimizar ou mesmo direcionar o desenvolvimento de uma espécie. Pesquisas de campo mostram que a desfolha induz alterações fisiometabólicas profundas nas relações fonte-dreno, como por exemplo na síntese e distribuição de fotoassimilados (Hanson \& West, 1982; Pandey, 1983; Wilkerson et al., 1984; Pechan \& Morgan, 1985). A remoção das flores, observada em lentilha (Lens esculenta L.) três semanas após a antese, em níveis de 25 a $75 \%$ reduziu sensivelmente a produção de sementes, porém, essa redução não foi proporcional ao grau de remoção (Pandey, 1983). Noda \& Kerr (1983), em um estudo realizado com a 
espécie jicama (Pachyrrhizus erosus (Urban)), onde avaliou-se a produção de raízes tuberosas em plantas com e sem tutor e com e sem inflorescência, verificaram que a retirada dos botões florais aumentou em até dez vezes a produção em peso das raízes e, que apesar dessa espécie ser uma planta trepadeira com crescimento indeterminado, os dados sugeriam não ser necessário tutoramento para aumentar a produção de raízes.

Sinha et al. (1977), ao estudarem também a espécie jicama, obtiveram uma correlação negativa entre produção de raízes e número de vagens por planta. Isso sugere que há migração de fotoassimilados para as flores, vagens e sementes, em detrimento da formação de raízes.

Noda et al. (1984) concluíram que a combinação tutoramento e retirada das inflorescências poderia aumentar a produção de raízes tuberosas em até dez vezes. Por sua vez Alvarenga (1987), em Campinas, (SP), verificou que, na primavera, a remoção de ramos laterais e inflorescências, praticadas isoladamente ou em combinação, não afetou o peso das raízes, enquanto que no outono, desfolhas de $33 \%$ e $66 \%$, associada à remoção de inflorescências, propiciou peso de raízes superior em relação ao plantio de primavera. Em estudos realizados por Zapeda (1971), os resultados mostraram que a retirada das inflorescências em jicama aumentou o tamanho e o rendimento das raízes, promovendo um incremento de até $114 \%$, em relação ao tratamento onde as inflorescências foram mantidas.

Costa (1994), estudando o efeito da poda da parte aérea e das raízes em mudas de tomateiro industrial, verificou que o tratamento sem poda proporcionou maior peso médio dos frutos $(83 \mathrm{~g})$ e maior produtividade $(66,0 \mathrm{t} / \mathrm{ha})$.

A importância do conhecimento do conteúdo de clorofila em folhas baseiase no seu relacionamento com a taxa fotossintética e o crescimento da planta (Boardman, 1977; Buttery \& Buzzel, 1977; Engel \& Poggiani, 1991). O rendimento fotossintético da planta por sua vez depende de vários fatores internos, como estrutura da folha, teor de clorofila e acúmulo de produtos da fotossín- tese dentro dos cloroplastos, além de fatores externos, como qualidade e quantidade de luz (Hall \& Rao, 1980).

Alvarenga (1987), em estudos realizados com a espécie feijão-macuco, verificou que o fotoperíodo afetou os níveis de clorofilas $\mathrm{a}, \mathrm{b}$ e total dos folíolos laterais da quinta folha trifoliolada, sem contudo alterar a relação clorofila a:b. Verificou, ainda, que a redução observada nos teores de clorofila não alterou o ganho de matéria seca das plantas, apesar de ter aumentado o número de folhas e suas respectivas áreas.

Esse trabalho teve como objetivo: a) avaliar o crescimento da espécie feijãomacuco, correlacionando o desenvolvimento de órgãos da planta nas fases vegetativa, de floração, de frutificação e da formação das raízes tuberosas; b) avaliar a importância do tutoramento e da eliminação da inflorescência no desenvolvimento da planta e na produção de raízes tuberosas.

\section{MATERIAL E MÉTODOS}

Este estudo foi desenvolvido na Estação Experimental do Ariau - Município de Iranduba, na margem esquerda do Rio Solimões, utilizando-se três genótipos da Coleção do Programa de Melhoramento de Hortaliças do Instituto Nacional de Pesquisas da Amazônia, identificadas como genótipos 1,2 e 3, no período de agosto de 1993 a maio de 1994, tendo-se verificado um total de $1.925 \mathrm{~mm}$ de chuva, temperatura média de $26^{\circ} \mathrm{C}$ e umidade relativa de $86,5 \%$.

Foram coletadas amostras de solo (0 a $25 \mathrm{~cm}$ de profundidade) no local de implantação do experimento, para determinação do pH e da fertilidade. Os resultados obtidos foram: $\mathrm{pH}$ em água $=4,68$; fósforo $=53 \mathrm{ppm} ;$ potássio $=$ 126 ppm; cálcio = 9,18 me\%; magnésio $=3,37$ me\%; alumínio = 0,90 me\%; manganês $=88 \mathrm{ppm} ;$ zinco $=26 \mathrm{ppm}$; ferro $=618 \mathrm{ppm}$.

A semeadura foi direta no campo, utilizando-se duas sementes por cova, em leiras com cerca de $20 \mathrm{~cm}$ de altura, utilizadas para proteger as plântulas na fase inicial de seu crescimento. $\mathrm{O}$ espaçamento foi de um metro entre linhas e de 0,5 metro entre plantas, e o delineamento experimental de blocos ao acaso, em esquema fatorial $3 \times 2 \times 2$ (três introduções, com e sem tutor, com e sem a retirada das inflorescências), com três repetições. O tamanho das parcelas foi de 15,5 x 25,0 m.

Durante a fase experimental as plantas apresentaram perfurações no limbo foliar, notadamente no início de seu desenvolvimento. Detectou-se que o principal ataque era devido a "vaquinhas", principalmente dos gêneros Eriopis e Cerotoma.

Para a identificação de doenças, fezse um levantamento avaliando a ocorrência das mesmas sobre as plantas e o nível de danos causados pelos patógenos. Observou-se que os principais problemas foram: ferrugem, causada por Fhakospsora pachyrhizi, observada em $100 \%$ das plantas; antracnose, causada por Colletotrichum $\mathrm{sp}$, ocorrendo em folhas e vagens; virose (mosaico) e murcha, causada por Sclerotium spp.

O tutoramento das plantas teve início quando as mesmas apresentavam o seu terceiro par de folhas trifolioladas, usando como tutor varas de madeira. A poda das inflorescências foi realizada semanalmente, quando as mesmas encontravam-se na fase de botão floral, tendo iniciado aos 70 dias após a semeadura.

Durante o desenvolvimento das plantas foram realizadas avaliações mensais do crescimento, até 175 dias após o plantio. A cada coleta realizouse um sorteio de três plantas por parcela, de modo que, para cada característica avaliada, calculou-se a média aritmética de três repetições, totalizando 36 plantas por bloco. As plantas foram arrancadas do solo com o auxílio de uma enxada, tomando-se o cuidado para não danificar o sistema radicular e a seguir, colocadas em sacos plásticos, etiquetadas por tratamento, colocadas em caixas de isopor contendo gelo e transportadas para o laboratório.

Antes de se iniciar as medições, as plantas foram cuidadosamente lavadas, secas e suas raízes tuberosas escovadas para a remoção de qualquer resíduo de solo.

Foi feita a contagem do número de folhas por planta e a medida da área 
foliar foi realizada com o auxílio do aparelho portátil LICOR LI 3.000. Para a determinação da biomassa dividiu-se a planta por partes (folhas, caule, flores, vagens, sementes e raízes). Cada uma dessas partes foi colocada em sacos de papel e levada a estufa a $80^{\circ} \mathrm{C}$ com circulação forçada de ar, até se obter peso constante. Após a secagem, obteve-se o peso da matéria seca, utilizando-se uma balança analítica modelo METTLER H35 AR. O desenvolvimento das raízes tuberosas foi avaliado através do peso da matéria fresca e da matéria seca acumulada. A razão de área foliar foi determinada por meio da relação $\mathrm{RAF}=\mathrm{AFE} \mathrm{x}$ $\mathrm{RPF}$, onde RAF é razão de área foliar; AFE área foliar específica e RPF razão do peso foliar, expresso em $\mathrm{cm}^{2} / \mathrm{g} / \mathrm{dia}$, segundo Benincasa (1986). A taxa de crescimento relativo foi avaliada considerando as diferenças de matéria seca acumulada em um período de trinta dias ao longo do desenvolvimento das plantas, sendo que na última coleta o intervalo foi reduzido para quinze dias, devido à cheia do rio Solimões. A equação utilizada para o cálculo da taxa de crescimento relativo foi: $\mathrm{TCR}=1_{\mathrm{n}} \mathrm{P}_{2}-1_{\mathrm{n}} \mathrm{P}_{1} / \mathrm{T}_{2}-\mathrm{T}_{1}$, expressa em g.g-1 dia (Magalhães, 1985) onde: $\mathrm{P}_{2}$ e $\mathrm{P}_{1}$ são pesos da matéria seca acumulada nos tempos $\mathrm{T}_{2}$ e $\mathrm{T}_{1}$.

Para obtenção dos teores de clorofilas a, b e total, foi selecionada a quinta folha trifoliolada. Para compor uma amostra, fez-se a homogeneização de três amostras provenientes de um mesmo tratamento. A seguir, retiraram-se seis discos foliares de $0,72 \mathrm{~cm}$, evitando-se a borda e a nervura central das folhas. Os discos foram pesados e macerados em acetona $80 \%$, com adição de $\mathrm{MgCO}_{3}$, a fim de evitar a feofitinização (Steffens $e t$

Tabela 1. Número de folhas por planta de feijão-macuco em diferentes estádios de desenvolvimento. Manaus, INPA, 1996.

\begin{tabular}{lcccccc}
\hline \multirow{2}{*}{ Tratamento } & \multicolumn{7}{c}{ dias após a semeadura } \\
\cline { 2 - 7 } & $\mathbf{4 0}$ & $\mathbf{7 0}$ & $\mathbf{1 0 0}$ & $\mathbf{1 3 0}$ & $\mathbf{1 6 0}$ & $\mathbf{1 7 5}$ \\
\hline Com tutor & $12,4 \mathrm{~b}$ & 12,6 & 28,6 & 34,6 & 47,3 & 36,7 \\
Sem tutor & $15,2 \mathrm{a}$ & 12,3 & 25,1 & 36,3 & 48,2 & 45,9 \\
\hline DMS & 2,16 & - & - & - & - & - \\
\hline
\end{tabular}

Médias seguidas de mesma letra nas colunas não diferem estatisticamente entre si a 5\% pelo teste de Tukey.

al., 1976) e centrifugados a $2.500 \mathrm{rpm}$ durante dez minutos. As absorbâncias dos extratos cetônicos foram determinadas em espectrofotômetro, a 645 nm e 663 nm e os cálculos das concentrações de clorofilas $\mathrm{a}, \mathrm{b}$ e total foram realizados com base nos coeficientes de Arnon (1949), expressos em miligramas por grama de material fresco:

clorofila $\mathrm{a}=(12,7 \mathrm{x}$ DO663 - 2,69 x DO 645) x V/1.000 x W;

clorofila $b=(22,9 \times$ DO645 - 4,68 x DO 663) x V/1.000 x W;

clorofila total $=(20,2 \times$ DO645 + $8,02 \times$ DO663) $\times$ V/1.000 x W;

onde: $\mathrm{V}=$ volume da amostra em mililitros; $\mathrm{W}=$ peso da amostra em gramas; $\mathrm{DO}=$ densidade ótica.

Para a análise dos dados utilizou-se o programa estatístico SAS (SAS, 1989). Na avaliação dos dados foi realizada análise de variância pelo teste $\mathrm{F}$ e comparação das médias pelo teste de Tukey, a 5\% de probabilidade (Gomes, 1977).

\section{RESULTADOS E DISCUSSÃO}

\section{Parte aérea e sistema radicular}

A análise estatística mostrou que a área foliar e a razão de área foliar não apresentaram diferenças significativas em nenhum dos tratamentos estudados e suas interações. Isso significa que tanto os genótipos como o manejo adotados não proporcionaram aumento foliar, apesar de ter sido eliminado na planta um dreno de fotoassimilados, que é a inflorescência. Nesse caso, outra parte da planta foi beneficiada com a alteração desse dreno metabólico.

Observou-se que apenas aos 40 dias as plantas não tutoradas apresentaram médias mais elevadas referentes ao número de folhas, quando comparadas com aquelas tutoradas (Tabela 1), mostrando que a diferença foi observada apenas no início do crescimento vegetativo e posteriormente as plantas cresceram de forma equilibrada, atingindo valores semelhantes.

Referente ao peso de matéria seca acumulada na parte aérea (Tabela 2), foram observadas diferenças significativas aos 160 dias para o caule e total, sendo o tratamento tutorado aquele que resultou em maior crescimento. As folhas não mostraram diferenças, enquanto que o caule sim, o que resultou em maior peso total da parte aérea. $\mathrm{O}$ aumento do peso da matéria seca do caule 160 dias nas plantas submetidas ao

Tabela 2. Peso de matéria seca da folha, caule e parte aérea de plantas de feijão-macuco em diferentes dias após semeadura e formas de manejo. Manaus, INPA, 1996.

\begin{tabular}{|c|c|c|c|c|c|c|c|c|c|c|c|c|c|c|c|c|c|c|}
\hline \multirow{3}{*}{ Tratamento } & \multicolumn{6}{|c|}{ Folha (g) } & \multicolumn{6}{|c|}{ Caule (g) } & \multicolumn{6}{|c|}{ Parte Aérea (g) } \\
\hline & \multicolumn{6}{|c|}{ (dias após a semeadura) } & \multicolumn{6}{|c|}{ (dias após a semeadura) } & \multicolumn{6}{|c|}{ (dias após a semeadura) } \\
\hline & 40 & 70 & 100 & 130 & 160 & 175 & 40 & 70 & 100 & 130 & 160 & 175 & 40 & 70 & 100 & 130 & 160 & 175 \\
\hline Com tutor & 2,2 & 3,9 & 10,8 & 15,5 & 22,6 & 20,6 & 0,5 & 3,2 & 7,7 & 16,9 & $34,6 a$ & 38,4 & 2,6 & 7,0 & 18,0 & 36,7 & $83,6 a$ & 101,4 \\
\hline Sem tutor & 2,8 & 3,7 & 8,4 & 11,6 & 17,8 & 20,3 & 0,5 & 3,0 & 7,3 & 10,8 & $20,1 b$ & 36,9 & 3,3 & 6,5 & 16,3 & 24,4 & $41,4 b$ & 79,4 \\
\hline Com infl. & 2,3 & 4,5 & 9,6 & 13,0 & 16,7 & $16,0 b$ & 0,4 & 3,4 & 8,3 & 14,0 & 25,7 & 32,2 & 2,8 & 7,6 & 17,6 & 31,7 & 69,0 & 105,8 \\
\hline Sem infl. & 2,7 & 3,1 & 9,7 & 14,1 & 23,7 & $25,0 a$ & 0,6 & 2,8 & 6,7 & 13,7 & 29,0 & 42,9 & 3,2 & 5,9 & 16,8 & 29,4 & 56,1 & 76,4 \\
\hline DMS (tutor) & - & - & - & - & - & - & - & - & - & - & 13,92 & - & - & - & - & - & 39,38 & - \\
\hline DMS (inflor) & - & - & - & - & - & 5,63 & - & - & - & - & - & - & - & - & - & - & - & - \\
\hline
\end{tabular}

Médias seguidas de mesma letra nas colunas não diferem significativamente entre si a $5 \%$ pelo teste de Tukey 
Tabela 3. Peso de matéria seca das raízes, parte aérea e total, em três genótipos de feijão-macuco, obtidos em diferentes dias após a semeadura e formas de manejo. Iranduba, INPA, 1996.

\begin{tabular}{|c|c|c|c|c|c|c|c|c|c|c|c|c|c|c|c|c|c|c|}
\hline \multirow{3}{*}{ Tratamento } & \multicolumn{6}{|c|}{ Raízes (g) } & \multicolumn{6}{|c|}{ Parte Aérea(g) } & \multicolumn{6}{|c|}{ Total $(g)$} \\
\hline & \multicolumn{6}{|c|}{ (dias após a semeadura) } & \multicolumn{6}{|c|}{ (dias após a semeadura) } & \multicolumn{6}{|c|}{ (dias após a semeadura) } \\
\hline & 40 & 70 & 100 & 130 & 160 & 175 & 40 & 70 & 100 & 130 & 160 & 175 & 40 & 70 & 100 & 130 & 160 & 175 \\
\hline Com tutor & 0,1 & $1,4 \mathrm{~b}$ & 5,2 & 7,9 & 25,1 & 32,8 & 2,6 & 7,0 & 18,0 & 36,7 & $83,6 a$ & 101,4 & 2,9 & 8,6 & 21,2 & 43,4 & $105,3 a$ & 128,6 \\
\hline Sem tutor & 0,4 & $2,0 a$ & 8,5 & 7,7 & 18,9 & 28,0 & 3,3 & 6,5 & 16,3 & 24,4 & $41,4 b$ & 79,4 & 3,6 & 8,4 & 25,9 & 31,3 & $57,5 b$ & 108,8 \\
\hline Com infl. & 0,3 & 1,9 & 7,1 & $6,0 b$ & $10,4 b$ & $16,5 b$ & 2,8 & 7,6 & 17,6 & 31,7 & 69,0 & 105,8 & 3,1 & 9,6 & 24,0 & 37,2 & 79,5 & 117,4 \\
\hline Sem infl. & 0,3 & 1,5 & 6,4 & $9,6 a$ & $33,5 a$ & $44,6 a$ & 3,2 & 5,9 & 16,8 & 29,4 & 56,1 & 76,4 & 3,5 & 7,5 & 23,1 & 37,5 & 83,5 & 121,2 \\
\hline DMS (tutor) & - & 0,46 & - & - & - & - & - & - & - & - & 39,38 & - & - & - & - & - & 43,40 & - \\
\hline DMS (inflor) & - & - & - & 3,12 & 9,64 & 12,01 & - & - & - & - & - & - & - & - & - & - & - & - \\
\hline
\end{tabular}

Médias seguidas de mesma letra nas colunas não diferem significativamente entre si a 5\% pelo teste de Tukey.

tutoramento, permitiu melhor distribuição e disposição das folhas, promovendo melhor interceptação relativa da luz solar do que nas plantas não tutoradas. Portanto, o tutoramento pode favorecer o crescimento em extensão do caule, decorrente da expansão dos primórdios foliares, do aumento de nós formados e do alongamento dos entrenós. Este último exige um suprimento contínuo de produtos fotossintetizados (Whatley \& Whatley 1982). Com relação à disposição das folhas, Mota (1979) ressalta que a fotossíntese, nas folhas com inclinação ótima, aumenta linearmente com a luz e que, para o uso eficiente da luz solar, a inclinação ótima deve ser de $81^{\circ}$, ou seja, uma posição mais ou menos ereta.

Aos 175 dias, o peso de matéria seca das folhas, para o tratamento com retirada das inflorescências, mostrou valor superior. Segundo Verkleyj \& Challa (1988), durante o crescimento, os fotoassimilados produzidos nas folhas (fonte) podem ser utilizados parcial ou temporariamente no crescimento da planta e/ou armazenados sob a forma de amido e açúcares, assim como podem ser exportados para outros órgãos. Tais substâncias podem acumular-se nas folhas, formando material não fotossintetizante, resultando, portanto, num maior acúmulo de matéria seca. Com a retirada das inflorescências, as raízes tuberosas passam a ser o principal dreno metabólico, e as folhas passam a exportar os fotoassimilados para a formação e desenvolvimento dessas raízes.

As plantas não tutoradas apresentaram, 70 dias após o plantio, peso de matéria seca das raízes superior ao das plantas submetidas ao tutoramento

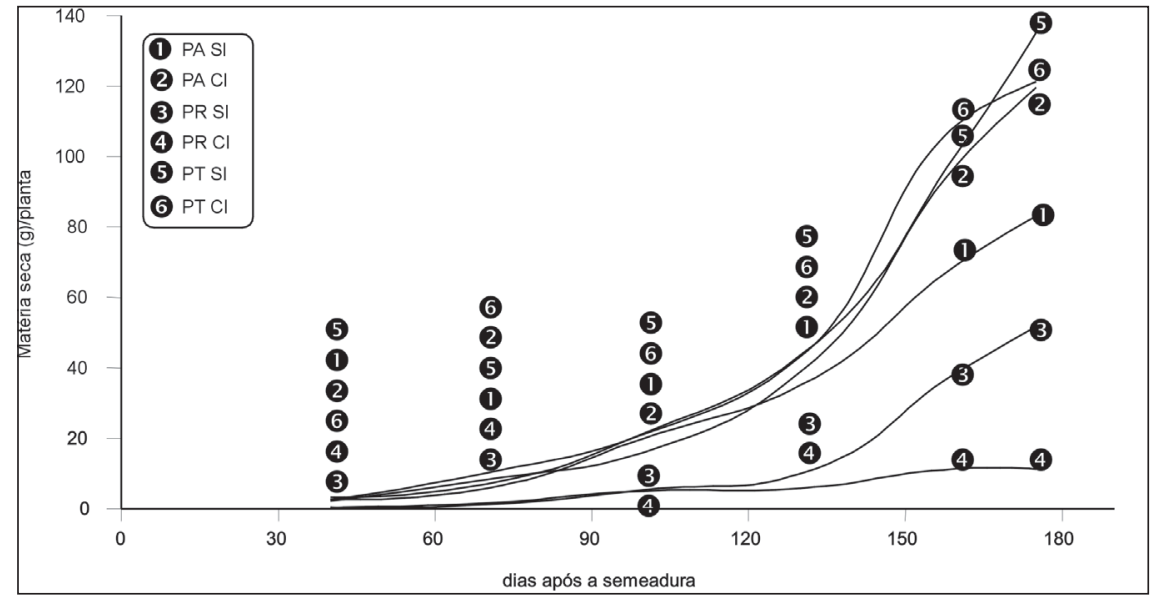

Figura 1. Peso da matéria seca acumulada na parte aérea (PA), raízes (PR) e total (PT) em plantas de feijão macuco tutoradas, com e sem inflorescências (CI e SI). Iranduba - AM, INPA, 1996.

(Tabela 3). Com relação aos demais períodos, o peso de matéria seca das raízes não foi influenciado pelo tutoramento. Esses resultados parecem indicar, que como as plantas começaram o processo de tuberização por volta dos 70 dias e que, em algumas plantas esse processo foi mais precoce do que em outras, essa desuniformidade pode ter ocasionado diferenças estatísticas em favor do tratamento sem tutoramento. Com relação aos demais períodos, não foram observadas diferenças significativas no peso de raízes, nas plantas submetidas ou não ao tutoramento. Verificou-se que, aos 130, 160 e 175 dias após a semeadura, no tratamento com poda de inflorescência o peso de raízes foi superior.

Vários autores (Zapeda, 1971; Meyer et al., 1973; Noda, 1979; Noda \& Kerr, 1983; Noda et al., 1984), mencionam que a prática da retirada das inflorescências proporciona um aumento considerável na produção de raízes tuberosas. Zapeda (1971), trabalhando com jicama, relata a necessidade dessa prática para duplicar o rendimento das raízes em termos de tamanho e peso. Meyer et al. (1973) mencionam que, em geral a remoção das flores, frutos ou gomos em desenvolvimento favorece $o$ crescimento radicular, podendo causar um decréscimo na razão caule-raiz.

A Tabela 3 mostra que o aumento do peso da matéria seca das raízes ocorreu quando as inflorescências foram retiradas das plantas (a poda teve inicio aos 70 dias após o plantio). A poda das inflorescências possibilitou a transferência preferencialmente de fotoassimilados para as raízes (maior dreno metabólico), resultando consequentemente, no aumento do peso da matéria seca. No final do ensaio, aos 175 dias após o plantio, as plantas tutoradas e com poda das inflorescências produziram cerca de 4,6 vezes mais raízes tuberosas do que o tratamento sem tutor e com inflorescências (Figura 1). 
Com relação ao peso da matéria seca da parte aérea, o maior acúmulo ocorreu nas plantas submetidas ao tratamento com tutor, 160 dias após a semeadura. Para os demais períodos, não se verificou diferenças estatísticas. Os tratamentos com e sem inflorescências não influenciaram no peso da matéria seca da parte aérea em todos os períodos analisados.

Os dados do peso de matéria seca acumulada na parte aérea, raízes e total em plantas de feijão-macuco com tutor e sem tutor são mostrados nas Figuras 1 e 2, respectivamente.

Com relação à retirada das inflorescências, observou-se que o peso da matéria seca das raízes foi significativamente superior nos tratamentos sem inflorescências que naqueles com inflorescências. Este resultado mostrou que os fotoassimilados que seriam utilizados para a formação das flores e posteriormente para vagens e sementes foram carreados para o sistema radicular, promovendo maior produção de raízes. Nas plantas submetidas ao tutoramento, a produção de raízes foi ainda mais evidente do que nas plantas não tutoradas. Isso se deve a uma melhor penetração e distribuição de luz solar por entre as folhas, facilitado pelo crescimento mais ordenado das plantas, conduzidas pelo tutor. Não foram observadas diferenças entre os genótipos utilizados.

Comparando-se a matéria seca nas raízes e na parte aérea (Figuras 1 e 2), observou-se que as plantas submetidas ao tratamento com tutoramento apresentaram um acúmulo de matéria seca da parte aérea e total superior aos das plantas não tutoradas. Observou-se ainda que as plantas, a partir de 120 dias após semeadura apresentaram tanto nos tratamentos com tutor e sem tutor, um aumento progressivo no crescimento, chegando a 175 dias após o plantio ao pleno desenvolvimento. Estes resultados parecem indicar que na época da última coleta, aos 175 dias após o plantio, as plantas ainda encontravam-se acumulando matéria seca e portanto em condições de desenvolvimento, podendo o ensaio ter sido prolongado por um período maior. Observou-se também que as plantas cultivadas com inflorescências tiveram um maior acúmulo de matéria

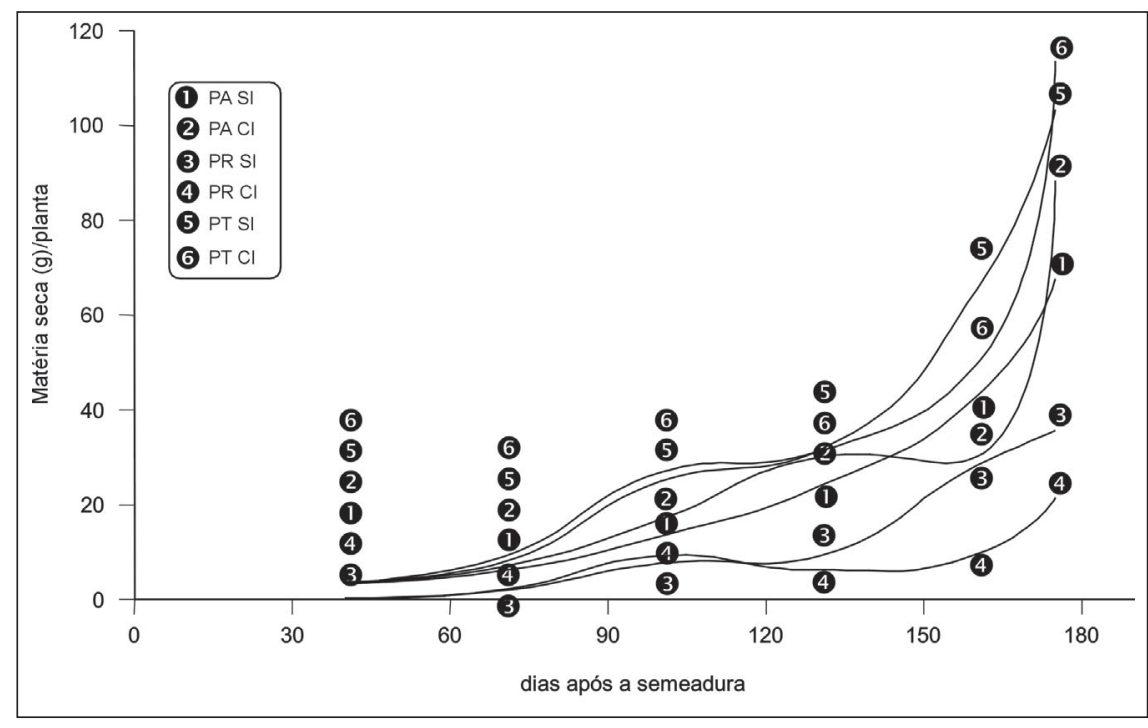

Figura 2. Peso da matéria seca acumulada na parte aérea (PA), raízes (PR) e total (PT) em plantas de feijão macuco sem tutor, com e sem inflorescências (CI e SI). Iranduba - AM, INPA, 1996.

seca da parte aérea, independente de terem sido ou não tutoradas. Quanto ao peso de matéria seca total, as plantas tutoradas apresentaram maior acúmulo quando submetidas ao tratamento sem inflorescências.

\section{Taxas de crescimento relativo}

Os genótipos estudados apresentaram uma tendência de taxa de crescimento relativo dentro de um mesmo padrão ao longo do seu desenvolvimento, em todos os períodos avaliados (Figura 3) .Observou-se também que nos genótipos 1 e 3 ocorreu um decréscimo na taxa de crescimento relativo das raízes no intervalo de tempo de 40-70 dias. Coincidentemente nesse período as raízes iniciaram a tuberização e, provavelmente, o processo não foi uniforme. Outro fator que pode ter contribuído para esse decréscimo foi que neste mesmo período as plantas sofreram grande ataque de vaquinhas e as folhas ficaram danificadas, prejudicando o processo de fotossíntese, a formação de fotoassimilados e, consequentemente, a tuberização. No intervalo de tempo de 70-100 dias, época em que as plantas estavam iniciando a floração, ocorreu decréscimo na taxa de crescimento dos frutos (considerados aqui a soma dos valores de flores, vagens e sementes), nos três genótipos estudados. Isto devese ao fato de que neste mesmo período também iniciou-se a tuberização.
Houve uma tendência das plantas tutoradas a apresentarem um maior crescimento relativo da raiz, caule, folha e fruto (Figura 3). Verificou-se que houve uma maior taxa de crescimento relativo da raiz nas plantas que foram simultaneamente tutoradas e desprovidas de inflorescências, reforçando os dados já discutidos de um crescimento mais ordenado nas plantas tutoradas. Verificou-se, ainda, um aumento acelerado na taxa de crescimento relativo do fruto a partir de 130 dias até 175 dias após a semeadura. Esse período também coincidiu com um aumento da área foliar. Estes dados confirmam os resultados encontrados por Alvarenga (1987), trabalhando com feijão-macuco que verificou aumentos na produção de vagens e sementes, coincidentes com o melhor desenvolvimento foliar.

\section{Teores de clorofilas}

O conteúdo de clorofilas em uma planta está diretamente relacionado com a capacidade de realizar a fotossíntese, cujo resultado ou produto final é o desenvolvimento do vegetal. Observou-se que 160 dias após a semeadura os teores de clorofilas obtidos em plantas onde as inflorescências foram removidas, apresentaram valores estatisticamente superiores ao tratamento sem poda (Tabela 4). Observou-se que os teores de clorofila a, 160 dias após o plantio, apresentaram diferenças significativas, em 


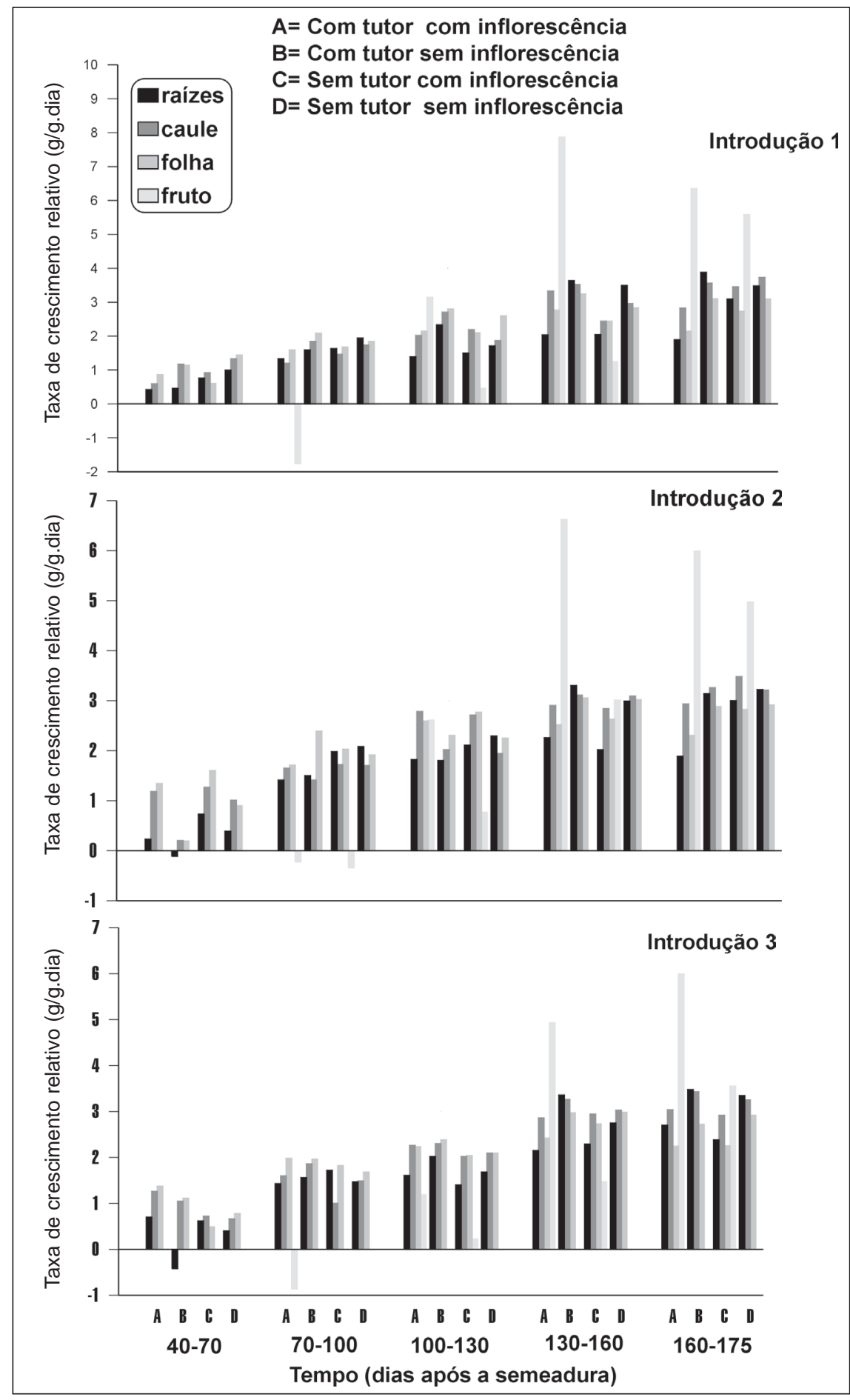

Figura 3. Taxa de crescimento relativo de três introduções de feijão macuco, em função do tempo. Iranduba - AM, INPA, 1996.

função dos tratamentos com ou sem inflorescências. Analisando-se os teores de clorofila $b$, verificou-se que apenas no período de 160 dias, ocorreram diferenças significativas quanto a forma de manejo. Os tratamentos sem inflorescências mostraram-se superiores e com diferenças significativas no teste $\mathrm{F}$ ao ní- vel de $5 \%$ e $1 \%$ de probabilidade nos teores de clorofilas a e b, respectivamente.

Com relação a clorofila total, os valores do teste $\mathrm{F}$, em função das formas de manejo foram não significativos, quando avaliados nos períodos de 40 , 100 e 130 dias após semeadura. Observou-se ainda que no tratamento com manejo das inflorescências, foram encontradas diferenças pelo teste $\mathrm{F}$, nos períodos de 70 e 160 dias (Tabela 4).

São escassas as informações sobre os efeitos fisiológicos da remoção das inflorescências sobre a tuberização e o conteúdo de clorofilas. Supõe-se que, com a retirada das inflorescências, seria eliminado um forte dreno metabólico, que é a floração e a formação de vagens e sementes. Com essa alteração, a planta passaria a deslocar maior quantidade de assimilados para a formação de raízes tuberosas e para o seu crescimento vegetativo, apresentando maior vigor e provável acúmulo de clorofilas nas folhas.

Os resultados obtidos neste trabalho, dentro das condições desenvolvidas, permitem concluir que:

A última coleta foi realizada aos 175 dias após a semeadura, quando as plantas ainda apresentavam incrementos de matéria seca nas diferentes partes, encontrando-se portanto em pleno desenvolvimento, indicando que seria viável permanecer por mais tempo no campo e provavelmente aumentar a produção de raízes. As plantas tutoradas apresentaram, de maneira geral, tendência a um desenvolvimento mais organizado, resultando num incremento ordenado das partes aérea e subterrânea, promovendo um maior rendimento das raízes. $\mathrm{O}$ tutoramento das plantas resultou em aumento do peso de matéria seca acumulada nos frutos, apesar de os mesmos não serem comestíveis e no momento utilizados apenas para a multiplicação das plantas. As taxas de crescimento de todos os genótipos apresentaram o mesmo padrão ao longo do desenvolvimento das plantas, considerando o período estudado. Observou-se uma tendência das plantas tutoradas a apresentarem uma maior taxa de crescimento relativo, indicando um maior acúmulo no peso da matéria seca, ou seja, maior crescimento. A remoção das inflorescências aumentou o peso de matéria seca acumulada das folhas, bem como a produção de raízes tuberosas, que associada ao tutoramento, produziu 4,6 vezes a mais, em peso, que o tratamento com inflorescências, sendo portanto recomendada essa prática cultural. 
Tabela 4. Teores de clorofilas a, b e total em plantas de feijão macuco, obtidas em diferentes períodos após semeadura, em função da poda de inflorescências. Iranduba, INPA, 1996.

\begin{tabular}{|c|c|c|c|c|c|c|c|c|c|c|c|c|c|c|c|}
\hline \multirow[t]{2}{*}{ Tratamento } & \multicolumn{5}{|c|}{$\begin{array}{c}\text { Clorofila a (mg/g MF) } \\
\text { (DAS) }\end{array}$} & \multicolumn{5}{|c|}{$\begin{array}{c}\text { Clorofila b (mg/g MF) } \\
\text { (DAS) }\end{array}$} & \multicolumn{5}{|c|}{$\begin{array}{l}\text { Clorofila total (mg/g MF) } \\
\text { (DAS) }\end{array}$} \\
\hline & 40 & 70 & 100 & 130 & 160 & 40 & 70 & 100 & 130 & 160 & 40 & 70 & 100 & 130 & 160 \\
\hline Com infl. & 1,86 & 1,29 & 1,51 & 1,53 & $1,38 b$ & 0,66 & - & 0,06 & 0,55 & $0,46 b$ & 2,56 & $1,29 a$ & 1,56 & 2,16 & $1,84 \mathrm{~b}$ \\
\hline Sem infl. & 1,98 & 1,18 & 1,51 & 1,63 & $1,67 a$ & 0,69 & - & 0,05 & 0,54 & $0,55 a$ & 2,56 & $1,12 b$ & 1,55 & 2,16 & $2,17 a$ \\
\hline$\overline{D M S}$ & - & - & - & - & 0,23 & - & - & - & - & 0,07 & - & 0,16 & - & - & 0,28 \\
\hline
\end{tabular}

Médias seguidas de mesma letra nas colunas não diferem significativamente entre si a 5\% pelo teste de Tukey.

\section{LITERATURA CITADA}

ALVARENGA, A.A. Estudos de alguns aspectos do desenvolvimento do feijão jacatupé (Pachyrrhizus tuberosus (Lam) Spreng). Campinas: Universidade Estadual de Campinas, 1987. 174 p. (Tese doutorado).

ARNON, D.I. Copper enzymes in isolated chloroplasts. Polyphenoloxidase in Beta vulgaris. Plant Physiology, v. 24, n. 1, p. 1-5, Jan. 1949.

BENINCASA, M.M.P. Análise de crescimento de plantas (noções básicas). São Paulo: Universidade Estadual Paulista, 1986. 41 p.

BOARDMAN, N.K. Comparative photosynthesis of sun and shade plants. Annual Review of Plant Physiology, v. 28, p. 355-377, 1977.

BUTTERY, B.R.; BUZZELL, R.I. The relationship between chlorophyll content and rate of photosynthesis in soybeans. Canadian Journal of Plant Science, v. 57, n. 1, p. 1-5, 1977

COSTA, N. D. Avaliação do efeito da poda da parte aérea e raízes em mudas de tomateiro industrial. In: RESUMOS DO CONGRESSO BRASILEIRO DE OLERICULTURA, XXXIV., 1984, Resumos... Brasília: Horticultura Brasileira, 1984. n. 12, v. 1, p. 77.

ENGEL, V.L.; POGGIANI, F. Estudo da concentração de clorofila nas folhas e seu espectro de absorção de luz em função do sombreamento em mudas de quatro espécies florestais nativas. Revista Brasileira de Fisiologia Vegetal, Brasília, v. 3, n. 1, p. 39-45, 1991.
GOMES, F.P. Curso de estatística experimental. São Paulo, Livraria Nobel S. A., 1977. 430 p.

HANSON, W.D.; WEST, D.R. Source-sink relationships in soybeans. I. Effects of source manipulation during vegetative growth on dry matter distribution. Crop Science, v. 22, n. 2, p. 372-376, 1982.

HALL, D.O.; RAO, K.K. Fotossíntese. São Paulo: E.P.D./ EDUSP, 1980. 89 p.

MAGALHÃES, A.C.N. Análise quantitativa do crescimento. In: FERRI, M. G. Ferri coord. Fisiologia Vegetal 1. São Paulo: EPU, 1985 p.

MEYER, B.S.; ANDERSON, D.B.; BOHNING R.H. Introdução à fisiologia vegetal. Lisboa: Fundação Calouste Gulbenkian, 1973. 564 p.

MOTA, F.S. Meteorologia agrícola. São Paulo: Livraria Nobel S.A., 1979. 376 p.

NODA, H. Potencialidade da cultura do feijãomacuco (Pachyrrhizus tuberosus) In: Von der Pahlen A.; Kerr W.E.; Paiva de O.W.; Rahman F.; Yuyama K.; Von der Pahlen E.; Noda H. eds. Introdução à horticultura e fruticultura no Amazonas. Manaus: CNPq/ INPA/ SUFRAMA, 1979. p. 58 - 65.

NODA, H.; KERR, W.E. The effects of staking and inflorescence pruning on the root production of yam bean (Pachyrrhizus erosus Urban). Tropical Grain Legume Bulletin, n. 27, p. 35-37, 1983.

NODA, H.; PAIVA, W.O.; BUENO, C.R. Hortaliças da Amazônia. Ciência Hoje, v. 3, n. 13, p. 32-37, Julho/Agosto 1984.

PANDEY, R.K. Effects of leaf and flower removal on seed yield of lentil (Lens esculenta L.). Journal of Agricultural Science, v. 100, p. 493 503, 1983.
PECHAN, P.A. ; MORGAN, D.G. Defoliation and its effects on pod and seed development in vil seed rape (Brassica napus L.). Journal of Experimental Botany, v. 36 , n. 164 , p. $458-468$, 1985.

SALES, A.M. Dados bioquímicos de Pachyrrhizus tuberosus e $P$. erosus. ITAL, Campinas (mimeografado), 1993. $03 \mathrm{p}$

SAS/STAT. Users guide, release ed. 6.04 Cary, NC SAS Institute Inc 1, 1989. 843 p.

SINHA, R.P.; PRAKASH, R.; HAQUE, Md F. Genotypic and phenotypic correlation studies in yam bean (Pachyrrhizus erosus Urban). Tropical Grain and Legume Bulletin, v.7, p.2425, 1977.

STEFFENS, D.P.; BLOS, J.; SCHOCH, S.; RUGIGER, W. Lichtabhaengigkeit der phytolakkumulation. Ein Beitrag zur Frage der Chlorophyll biosynthese. Planta, v. 130, p. 151-158, 1976.

VERKLEIJ, F.N.; CHALLA, H. Diurnal export and carbon economy in an expanding source leaf of cucumber at contrasting source and sink temperature. Physiologia Plantarum, v.74, p. 284- 293, 1988

WHATLEY, J.M. ; WHATLEY, F.R. A luz e vida das plantas. São Paulo: E.P.D./EDUSP, 1982. $101 \mathrm{p}$.

WILKERSON, G.G.; JONNES, J.W.; POE, S.L. Effects of the defoliation on peanut plant growth. Crop Science, v. 24, n. 3, p. 531- 536, 1984.

ZAPEDA, A.H. Efecto de desfloracion de la jicama (Pachyrrhizus erosus) sobre el rendimiento. American Society for Horticultural Science, v. 15, p. 18-24, 1971. 